\title{
Future options for disease intervention: important advances in phosphodiesterase
}

\section{4 inhibitors}

\section{R.A. Mclvor}

ABSTRACT: Current drug treatments for chronic obstructive pulmonary disease (COPD) focus on managing symptoms of the disease and include short- and long-acting $\beta_{2}$-agonists, anticholinergic agents (ipratroprium, tiotropium), methylxanthines (theophylline) and inhaled corticosteroids (ICS).

Cyclic nucleotide phosphodiesterases (PDEs) play a key role in cell signalling by degrading cyclic adenosine monophosphate (cAMP) and cyclic guanosine monophosphate. PDE4 is expressed in inflammatory cells and inhibition of this enzyme enhances the anti-inflammatory effects of CAMP in all key cells involved in COPD. Two PDE4 inhibitors, roflumilast and cilomilast, have been extensively evaluated in patients with COPD. Results from patients with moderate-tosevere and severe-to-very severe COPD have shown that roflumilast significantly improves forced expiratory volume in one second (FEV1) and significantly decreases exacerbations, particularly in patients with severe disease. Roflumilast is well tolerated with a low incidence of gastrointestinal adverse events that declines with continued treatment. Clinical trials with cilomilast have produced more varied results. Significant improvements in FEV 1 and reductions in exacerbation rates versus placebo were observed in two of four trials. Cilomilast also has a high risk for gastrointestinal adverse events that does not appear to dissipate over 24 weeks of treatment.

While further research is needed to fully determine the place in chronic obstructive pulmonary disease therapy for phosphodiesterase 4 inhibitors, they have several important potential benefits in the treatment of this disease, including convenient once-daily oral administration and freedom from adverse effects associated with corticosteroids. The fact that phosphodiesterase 4 inhibitors have potent anti-inflammatory effects and are administered orally, thereby reaching the systemic circulation, may decrease the severity of systemic comorbidities in chronic obstructive pulmonary disease patients.

KEYWORDS: Anti-inflammatory, chronic obstructive pulmonary disease, cilomilast, cyclic adenosine monophosphate, roflumilast

hronic obstructive pulmonary disease (COPD) is a chronic inflammatory condition. The risk for this disease is greatly increased by cigarette smoking but it occurs in both smokers and nonsmokers [1]. A large body of data has shown that cigarette smoking activates macrophages, dendritic cells and airway epithelial cells. Once activated, these cells release mediators that recruit and activate CD8+ T-lymphocytes and neutrophils (fig. 1) [2]. The inflammatory process mediated by these cells, and the cytokines and other molecules they release, promotes fibroblast proliferation and airway remodelling that eventually leads to obstructive bronchiolitis. Macrophages and neutrophils also release proteases that break down connective tissue, producing emphysema and stimulating mucus hypersecretion [2]. COPD is associated with a wide range of systemic comorbidities (e.g. cachexia, skeletal muscle dysfunction, osteoporosis) that are also thought to be associated with the abnormal inflammatory processes characteristic of this disease [3-5].

Current treatments for COPD focus on managing symptoms of the disease (i.e. dyspnoea) and include short- and long-acting $\beta_{2}$-agonists, anticholinergic agents (ipratroprium, tiotropium), methylxanthines (theophylline), inhaled corticosteroids (ICS) and combination products
CORRESPONDENCE

R.A. Mclvor

Room T2127

Firestone Institute for Respiratory Health

St Josephs Health Care

50 Charlton Avenue East L8N 4A6 Hamilton ON Canada Fax: 19055216183

E-mail: amcivor@stjosham.on.ca

STATEMENT OF INTEREST

R.A. Mclvor has received fees for speaking and consulting. The author has also received honoraria for continuing medical education and attendance at the advisory board meetings of Altana, a Nycomed company. 


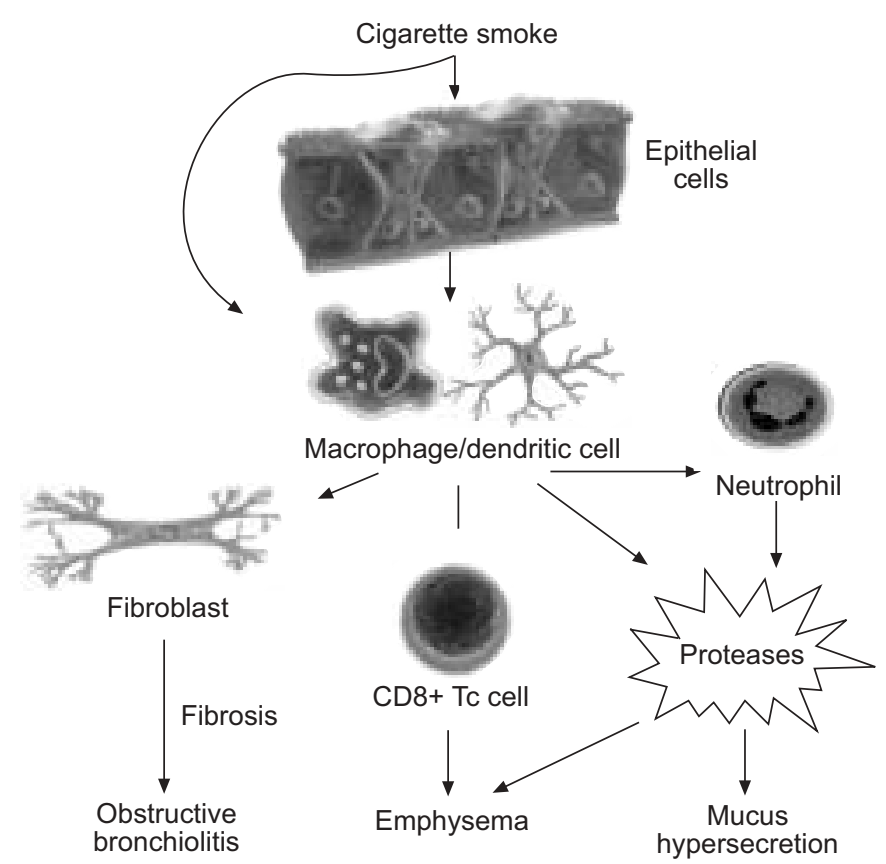

FIGURE 1. Several cells and inflammatory mediators are likely to be involved in chronic obstructive pulmonary disease (COPD). COPD is characterised by inflammation with macrophages and neutrophils. Many chemokines and cytokines have now been implicated in COPD, and inflammation in this disease is thought to stimulate excess mucus production, fibrosis and proteolysis. Tc cell: T-lymphocyte. Reproduced and modified from [2] with permission from the publisher.

(short-acting $\beta_{2}$-agonist plus an anticholinergic, long-acting $\beta_{2^{-}}$ agonist plus corticosteroid), and systemic corticosteroids.

While all of these treatments have been demonstrated to improve symptoms in patients with COPD, only the recently completed TOwards a Revolution in COPD Health (TORCH) study has demonstrated a significant treatment benefit in slowing disease progression and decreasing mortality in largescale, long-term controlled clinical trials $[1,2,6]$.

New medications, particularly an orally administered antiinflammatory agent, have been long awaited in COPD [7]. Several new treatments for COPD are in clinical development, some of which target the abnormal inflammatory process underlying this disease and have the potential to alter its natural history. These include phosphodiesterase (PDE) 4 inhibitors, leukotriene modifiers, tumour necrosis factor (TNF)- $\alpha$ antagonists, tyrosine kinase antagonists, inhibitors of nuclear factor (NF)- $\mathrm{kB}$, neutrophil elastase inhibitors, chemokine antagonists, mucolytics and novel antibiotics [2]. Among these, clinical development has been most extensive for PDE4 inhibitors and the present article reviews the most recent information for these drugs.

\section{PHOSPHODIESTERASES}

The PDE superfamily represents 11 gene families (PDE1 to PDE11). Each family encompasses one to four distinct genes, giving rise to $>20$ genes in mammals encoding the $>50$ different PDE proteins. Alterations in PDE activity have been implicated in many chronic conditions, including inflammation, neurodegeneration and cancer; inhibition of specific dysregulated PDEs has been proposed as potential therapy for these conditions [8]. In COPD, increases in cyclic adenosine monophosphate (cAMP) levels, activation of protein kinase A and enhanced protein phosphorylation have the potential to reduce inflammation, relax airway smooth muscle, inhibit chemotaxis and abnormal release of inflammatory and cytotoxic mediators, and decrease proliferation and migration of inflammatory cells [9]. Preventing breakdown of cAMP to 5AMP in neutrophils decreases TNF- $\alpha$ and $N$-formyl-methionylleucylphenylamine-stimulated neutrophil adherence, production of reactive oxygen species and degranulation [10].

PDE4 has been most extensively studied in COPD. The observations that PDE4 is expressed predominantly in inflammatory cells, such as neutrophils, CD8+ lymphocytes and macrophages, and is upregulated in the setting of pulmonary inflammation [11] have made this enzyme an attractive target for the development of new drugs to treat COPD [12]. PDE4 inhibitors specifically prevent the degradation of cAMP and have multiple anti-inflammatory effects, including inhibition of cell trafficking, and cytokine and chemokine release from inflammatory cells (neutrophils, eosinophils, macrophages and T-cells) [13].

\section{PDE INHIBITION IN THE TREATMENT OF COPD}

Theophylline is a broad-spectrum PDE inhibitor that has been used to treat pulmonary disease for many years. While theophylline has some benefit in the treatment of COPD, it is a weak and nontargeted PDE inhibitor that inhibits most of the 11 families of PDE in all tissues throughout the body; its use has been associated with a wide range of treatment-limiting side effects, including seizures and cardiac arrhythmias [9]. Research carried out over the past decade has led to the development of PDE4 inhibitors with the potential to significantly enhance treatment of patients with COPD. The remainder of the present article focuses on the two agents in this class that have been evaluated most extensively in controlled clinical trials, namely roflumilast and cilomilast.

\section{BIOCHEMISTRY OF SELECTIVE PDE4 INHIBITORS}

Both roflumilast and cilomilast are PDE4 inhibitors (table 1). Roflumilast does not affect other PDE isoenzymes, including PDE1, $-2,-3$ and -5 , at concentrations up to 10,000-fold higher than those which inhibit PDE4 concentrations [14]. Results from biochemical studies have also demonstrated that roflumilast is a substantially more potent blocker of PDE4 than cilomilast. The two agents have $50 \%$ inhibitory concentration (IC50) values of 0.0008 and $0.12 \mu \mathrm{mol} \cdot \mathrm{L}^{-1}$, respectively, for inhibition of this enzyme [14].

\section{BIOLOGICAL ACTIVITY}

The biological activities of roflumilast and cilomilast have been compared in several pre-clinical studies and results from these trials have confirmed the previously noted difference in the respective potencies of these two PDE4 inhibitors.

Mucus hypersecretion is a common feature of COPD and expression of MUC5AC, the predominant mucin gene in healthy airways, is increased in patients with this disease. MATA et al. [15] assessed the effects of roflumilast and cilomilast on MUC5AC mRNA, and protein expression in cultured human airway epithelial cells and in isolated human 


\begin{tabular}{lccc} 
TABLE 1 & $\begin{array}{l}\text { Selectivity of roflumilast, its major metabolite and } \\
\text { cilomilast for inhibition of phosphodiesterase } \\
\text { (PDE)4 activity }\end{array}$ \\
& Roflumilast & $\mathbf{N}$-oxide & Cilomilast \\
\hline PDE1 & $>10$ & $>10$ & 74 \\
PDE2 & $>10$ & $>10$ & 65 \\
PDE3 & $>10$ & $>10$ & $>100$ \\
PDE4 & 0.0008 & 0.002 & 0.12 \\
PDE5 & 8 & $>10$ & 83 \\
\hline
\end{tabular}

Data are given as mean $50 \%$ inhibitory concentrations (IC50) values $\left(\mu \mathrm{mol} \cdot \mathrm{L}^{-1}\right.$ ) calculated from concentration-inhibition curves by nonlinear regression analysis. Roflumilast inhibits PDE4 activity from human neutrophils with an IC50 value of $0.8 \mathrm{nM}$ without affecting PDE1 (bovine brain), PDE2 (rat heart), and PDE3 and PDE5 (human platelets), even at 10,000-fold higher concentrations. Roflumilast is almost equipotent to its major metabolite formed in vivo (roflumilast $\mathrm{N}$-oxide) and $>100$-fold more potent than cilomilast. Data from [14]. bronchial tissue stimulated with epidermal growth factor (EGF; $\left.25 \mathrm{ng} \cdot \mathrm{mL}^{-1}\right)$. Study results showed that EGF exposure increased MUC5AC mRNA and protein expression that was suppressed in a concentration-dependent manner by PDE4 inhibitors (fig. 2) with roflumilast exhibiting higher potency (as reflected by IC50 values) than either cilomilast or rolipram. The rank order of potencies (-log IC50 values) was as follows: roflumilast $(7.59)>$ rolipram $(6.66)>$ cilomilast $(5.58)$ for MUC5AC mRNA; and roflumilast (7.37) > rolipram (6.17) > cilomilast (5.27) for MUC5AC protein [15]. Results from in vitro studies of human neutrophils have shown further that roflumilast is substantially more potent than cilomilast in inhibiting release of neutrophil elastase, matrix metalloproteinase and myeloperoxidase [16].

Results from another recently published study in experimental animals have shown that roflumilast partially ameliorates lung inflammation and fully prevents parenchymal destruction induced by cigarette smoke. In the study by MARTORANA et al. [17], roflumilast was given orally at a dose of 1 or $5 \mathrm{mg} \cdot \mathrm{kg}^{-1}$ in an acute model of smoking (five cigarettes for $20 \mathrm{~min}$ ) and bronchoalveolar lavage fluid (BALF) changes were investigated
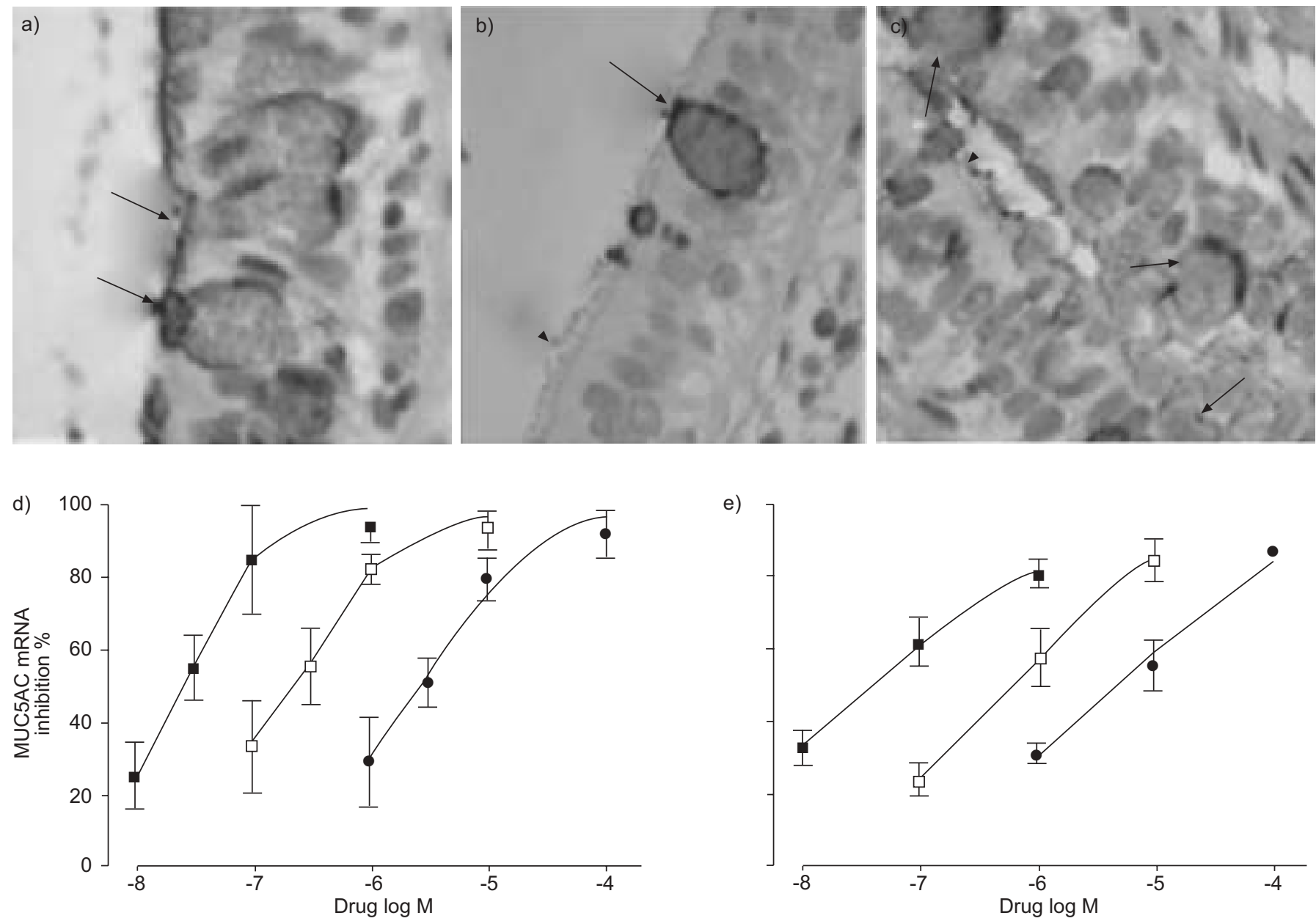

e)

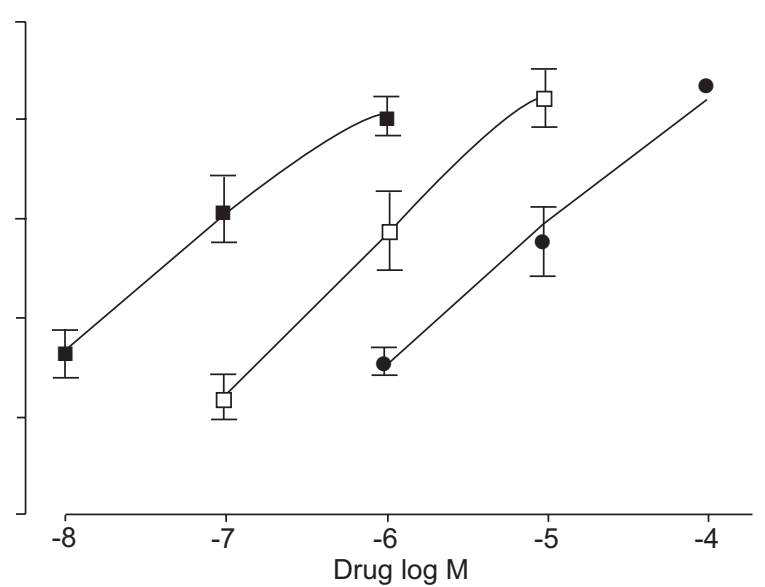

FIGURE 2. Study results for a) normal human lung tissue, b) epidermal growth factor (EGF)-stimulated tissue in the presence of roflumilast and c) effects of EGF only. Concentration-response curves are shown for inhibition by the selective phosphodiesterase (PDE) 4 inhibitors roflumilast ), cilomilast $(\bullet)$, and rolipram $(\bigcirc)$ of the EDFinduced expression of MUC5AC mRNA (d) and protein (e) in airway epithelial cells. Arrows: MUC5AC-positive goblet cells; arrowheads: unstained ciliated cells. Reproduced and modified from [15] with permission from the publisher. 


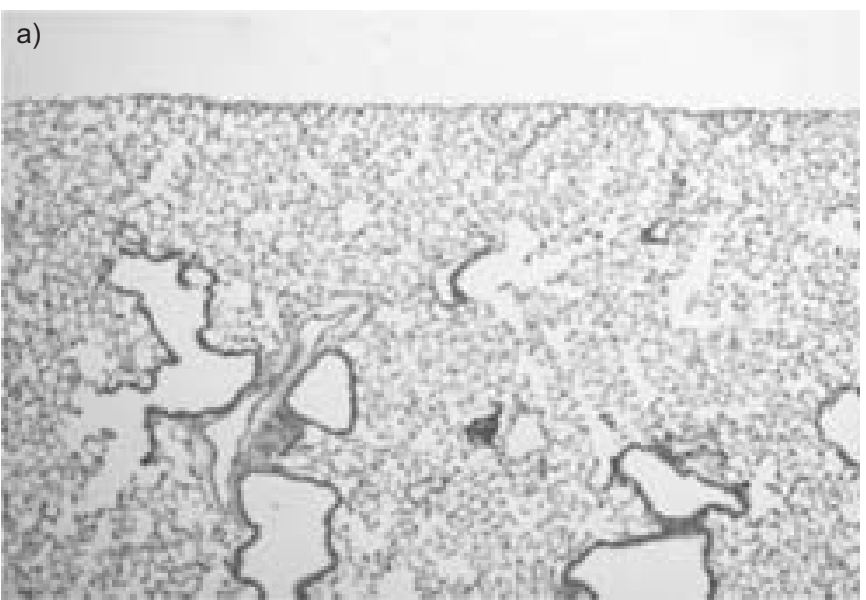

b)

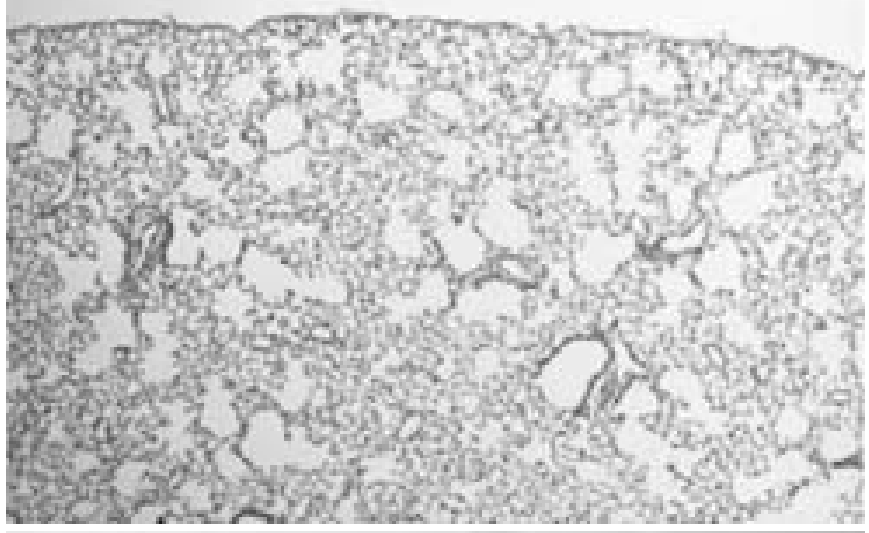

c)

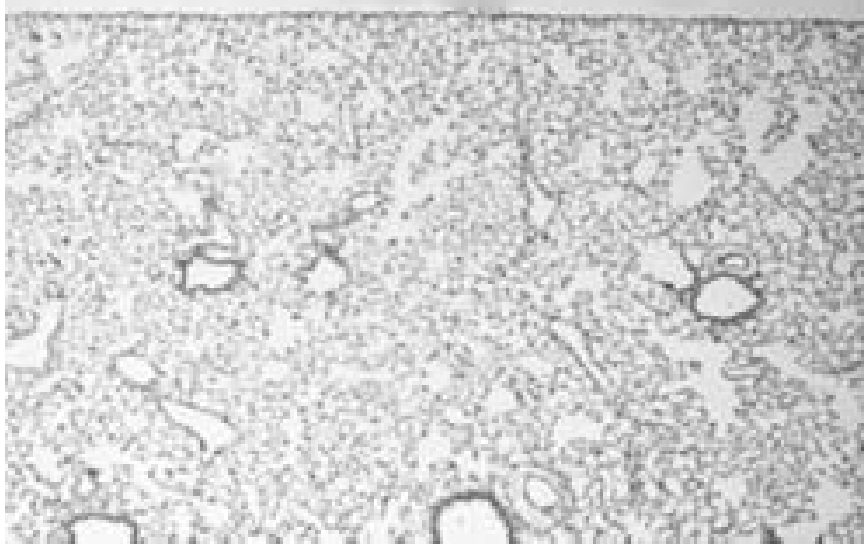

FIGURE 3. Roflumilast prevents elastolytic parenchymal destruction induced by chronic cigarette smoke. Lungs exposed to air had normal parenchyma and airways (a), whereas lungs exposed to chronic cigarette smoke showed foci of emphysema throughout the lung parenchyma (b). Lungs from animals treated with $5 \mathrm{mg} \cdot \mathrm{kg}^{-1}$ roflumilast (c), had a normal parenchyma, similar to that seen in the lungs of air-exposed mice. Reproduced and modified from [17] with permission from the publisher.

at 4 and $24 \mathrm{~h}$ after cigarette smoke exposure. In a second experiment, morphometric and biochemical parameters were evaluated after animals were exposed to the equivalent of three cigarettes per day for 7 months. Results from the first study showed that acute exposure to cigarette smoke

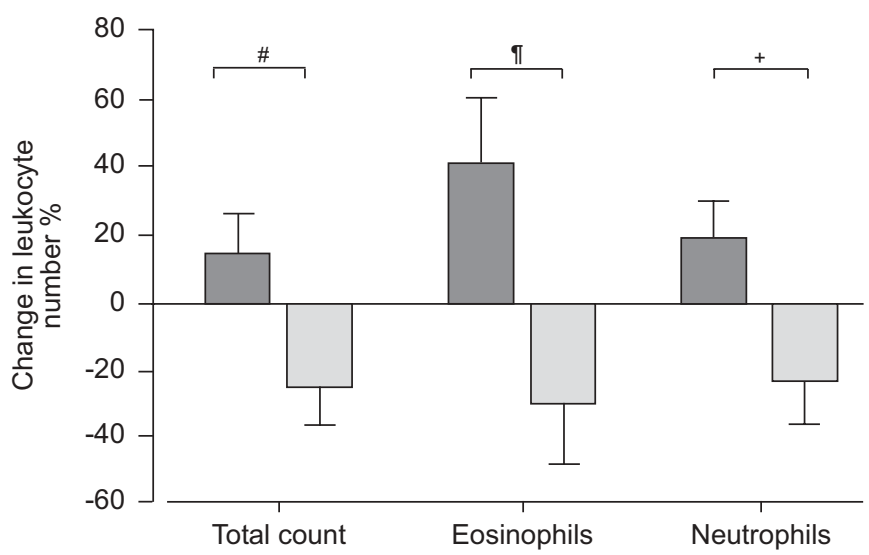

FIGURE 4. Changes in sputum leukocyte counts in chronic obstructive pulmonary disease patients treated with $500 \mu \mathrm{g}$ once daily roflumilast ( $\square$ ) or placebo ( $\square$ ). Results are from a 12-week, placebo-controlled crossover study that included 4 weeks in each study condition separated by a 4-week placebo washout period. ${ }^{*}: p=0.0023 ;{ }^{\bullet}: p=0.0005 ;{ }^{+}: p=0.0017$. Reproduced and modified from [18] with permission from the publisher

resulted in a five-fold increase in BALF neutrophils and that both roflumilast doses attenuated this increase by $\sim 30 \%$. Chronic smoke exposure caused a 1.8-fold increase in lung macrophage density, emphysema, an increase of the mean linear intercept $(+21 \%)$, a decrease of the internal surface area $(-13 \%)$ and a drop $(-13 \%)$ in lung desmosine content. Furthermore, in the study by MARTORANA et al. [17], the 5$\mathrm{mg} \cdot \mathrm{kg}^{-1}$ dose of roflumilast decreased the elevation in lung macrophage density by $70 \%$ and fully prevented the other pulmonary structural changes (fig. 3) [17].

\section{ANTI-INFLAMMATORY EFFECTS OF PDE4 INHIBITION IN PATIENTS WITH COPD}

The anti-inflammatory effects of roflumilast (500 $\mu \mathrm{g}$ once daily) have been evaluated in COPD patients in a 12-week, placebo-controlled crossover study that included 4 weeks in each study condition separated by a 4 -week placebo washout period [18].

Roflumilast treatment was associated with an $\sim 40 \%$ reduction in sputum leukocyte number versus placebo (fig. 4). The majority of this difference was accounted for by changes in neutrophil number. However, eosinophils were also significantly reduced by roflumilast therapy compared to placebo.

Inflammatory mediator levels were also significantly decreased by roflumilast. With placebo treatment, interleukin-8, a neutrophil chemotactic cytokine, increased by $\sim 10 \%$ above baseline. However, with roflumilast it decreased by $\sim 20 \%$ $(p=0.044)$. A similar pattern was observed for cell-free neutrophil elastase (roflumilast versus placebo; $\mathrm{p}=0.028$ ), which is released from neutrophils present in sputum.

The differences in effects on inflammatory markers observed with roflumilast versus placebo were paralleled by changes in postbronchodilator forced expiratory volume in one second (FEV1). There was a $40-\mathrm{mL}$ increase during treatment with roflumilast versus an $\sim 20-\mathrm{mL}$ decline during the placebo treatment period $(\mathrm{p}=0.018)$ [18]. 

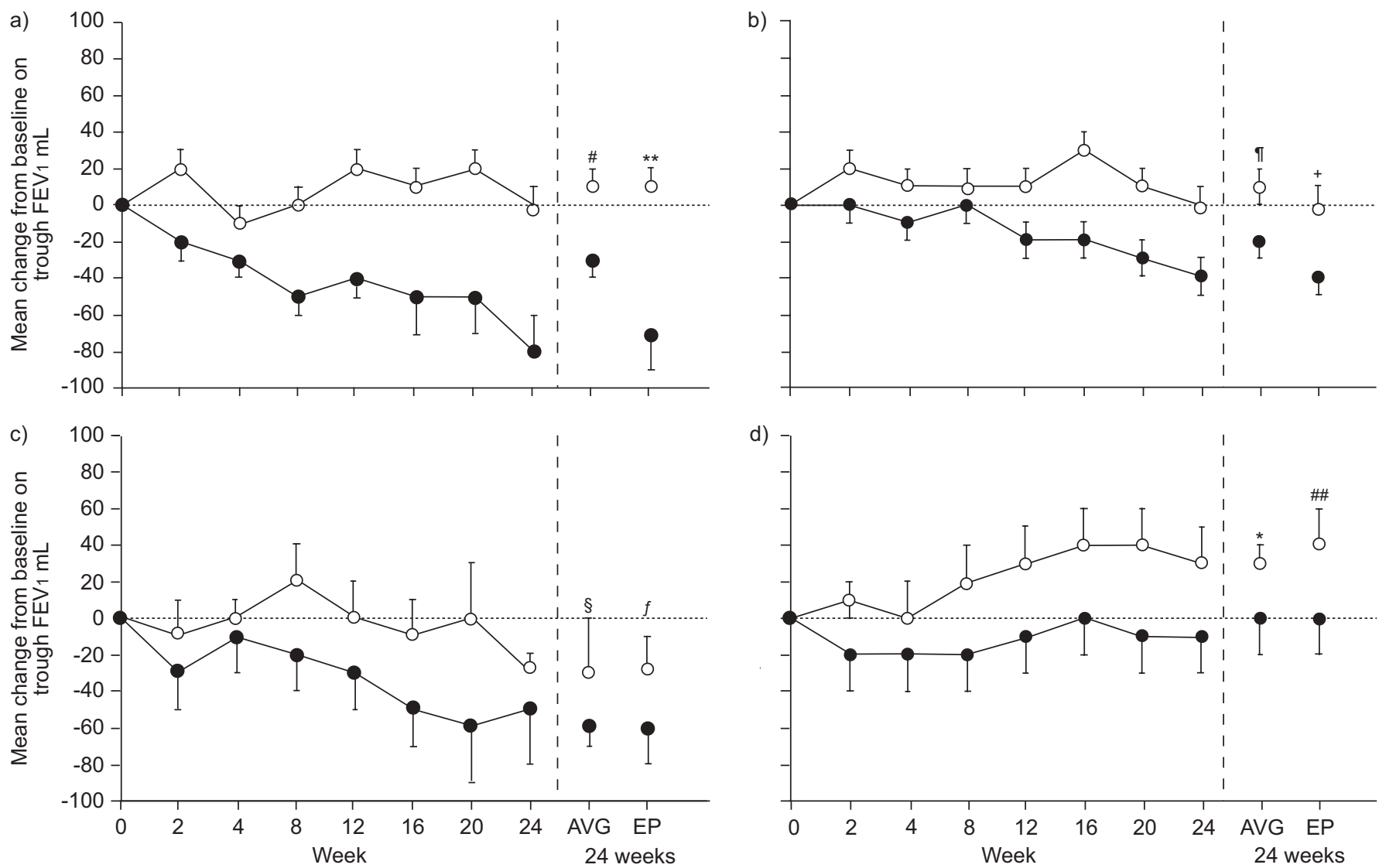

FIGURE 5. Effects of cilomilast (15 mg b.i.d.) and placebo on forced expiratory volume in one second (FEV1) in four pivotal 24-week trials: a) study 039, phase 3; b)

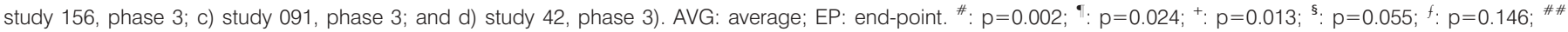
$p=0.044$. $: p=0.05 ; * *: p=0.001$. Reproduced and modified from [19] with permission from the publisher.

\section{CLINICAL TRIALS WITH ROFLUMILAST AND CILOMILAST}

Both cilomilast and roflumilast have been evaluated in multiple, placebo-controlled clinical trials.

\section{Cilomilast}

\section{Efficacy}

Clinical results for cilomilast have indicated variable efficacy and modest benefits in improving FEV1. The efficacy of cilomilast in COPD has been evaluated in four pivotal, multicentre, randomised, double-blind, placebo-controlled parallel-group studies with similar designs. Each compared $15 \mathrm{mg}$ b.i.d. cilomilast with placebo over 24 weeks. The primary efficacy end-points in these studies were change from baseline in trough FEV1 and total St George's Respiratory Questionnaire (SGRQ) score [19].

Results for FEV1 from the four studies are shown in figure 5. In three of the four trials (numbers 039, 42 and 156), cilomilast treatment produced modest improvements versus placebo in FEV1. Importantly, the statistical significance achieved in these trials was primarily due to deterioration in trough FEV1 for patients in the placebo group, which was most pronounced in the first 2-4 weeks of the study. Results from a fourth study (number 091) indicated no significant benefit of cilomilast over placebo $[19,20]$. When results from the four studies were pooled for analysis, the mean SGRQ score was reduced by -1.34 points for the subjects treated with cilomilast versus those who received placebo. This small difference was not viewed as being clinically meaningful. Cilomilast increased exacerbationfree survival and decreased the relative risk of experiencing at least one level 2 or level 3 COPD exacerbation, respectively, in only one of the four studies [19].

\section{Safety}

Combined safety results for cilomilast in the four previously described studies are presented in table 2. Of the patients in the placebo and cilomilast groups, $>75 \%$ experienced at least one adverse event. The most common side effects for cilomilast involved the gastrointestinal system. Nausea occurred about three times more often with cilomilast than with placebo, diarrhoea was twice as common with cilomilast as with placebo, and vomiting occurred nearly four times more often with cilomilast versus placebo. Analysis of the timing of gastrointestinal adverse events in the four studies indicated that their frequency did not decline substantially with continued therapy over 24 weeks [20]. It has been suggested that the high risk for gastrointestinal adverse events in patients receiving cilomilast may be related to the fact that it selectively inhibits ( 10-fold) an isoform of PDE4 (PDE4D), which has been shown to be involved in suppression of emesis [18, 21, 22]. In mice and humans, PDE4D is found in the area postrema 


\begin{tabular}{llc}
\hline TABLE 2 & $\begin{array}{l}\text { Most common adverse events experienced by } \\
\text { chronic obstructive pulmonary disease patients } \\
\text { treated with cilomilast or placebo in four clinical } \\
\text { trials with this phosphodiesterase }\end{array}$ \\
& Placebo & inhibitor. \\
& & Cilomilast \\
\hline & 1091 & 1792 \\
Patients n & 76.9 & 78.3 \\
Adverse event & 36.2 & 30.4 \\
COPD & 5.0 & 15.7 \\
Nausea & 7.9 & 14.4 \\
Diarrhoea & 7.1 & 11.7 \\
Abdominal pain & 10.3 & 8.8 \\
Upper respiratory tract & & \\
$\quad$ infection & 7.0 & 8.2 \\
Headache & 2.5 & 6.8 \\
Dyspepsia & 1.6 & 6.1 \\
Vomiting & 5.0 & 5.4 \\
Injury & 5.3 & 3.5 \\
Coughing & & \\
\hline
\end{tabular}

Data presented as \%, unless otherwise stated. From [20]

and the nucleus tractus solitarious, brain structures which are implicated in the emetic response [21, 22]. Unlike cilomilast, roflumilast exhibits little selectivity for PDE4D versus either PDE4A or B [18], and this may contribute to its low risk for gastrointestinal adverse events compared to cilomast (discussed further later).

\section{Roflumilast}

Roflumilast is a much more potent inhibitor of PDE4 than cilomilast [15], which suggests that it may have greater benefit in patients with COPD. Results for clinical trials carried out to date support this suggestion.

\section{Efficacy}

The efficacy of roflumilast has been assessed in two large-scale clinical trials in patients with moderate-to-severe and severeto-very severe COPD.

\section{Moderate-to-severe COPD trial}

RABE et al. [23] evaluated the safety and efficacy of roflumilast ( 250 or $500 \mu \mathrm{g}$ once daily) versus placebo in 1,411 patients with moderate-to-severe COPD in a multicentre, double-blind, randomised parallel-group study. The primary efficacy endpoints in this trial were postbronchodilator FEV1 and healthrelated quality of life as measured by SGRQ. Patients enrolled in this study had suffered from COPD for $\geqslant 12$ months, were $\geqslant 40 \mathrm{yrs}$ of age, had postbronchodilator FEV1/forced vital capacity (FVC) $\leqslant 70 \%$ and FEV1 $30-80 \%$ predicted [23]. Both roflumilast doses increased postbronchodilator FEV1 from baseline versus a decline with placebo (fig. 6). Both roflumilast doses significantly increased FEV1 from baseline at all study visits $(p<0.05)$, and these improvements for both doses were also significantly different from results from the placebo group $(p<0.03)$, which had a steady decline in FEV1 over the course of treatment. At 24 weeks, the improvement in FEV1 for $500 \mu \mathrm{g}$ roflumilast versus placebo was $97 \mathrm{~mL}$ [23].

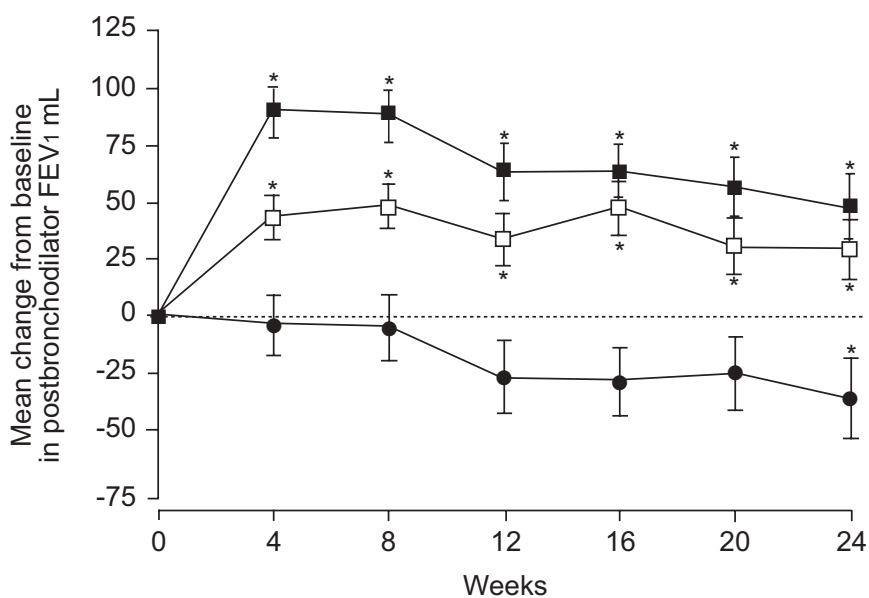

FIGURE 6. Change from baseline in postbronchodilator forced expiratory volume in one second ( $\left.F E V_{1}\right)$ over time in patients treated with roflumilast or placebo. Results are from a 24-week, multicentre, double-blind, randomised parallel-group study of the safety and efficacy of roflumilast (250 ( $\square$ ) or $500 \mu \mathrm{g}(\boldsymbol{\square})$ once daily) versus placebo (-) in 1,411 patients with chronic obstructive pulmonary disease. *: $p<0.05$ versus baseline. Reproduced and modified from [23] with permission from the publisher.

Health-related quality of life assessed by SGRQ improved in patients treated with either roflumilast or placebo. The change from baseline in SGRQ scores for patients who received roflumilast $500 \mu \mathrm{g}$ or placebo were -3.5 units $(\mathrm{p}<0.0001)$ and -1.8 units $(p=0.0271)$, respectively [23].

Treatment with roflumilast also significantly decreased the risk for acute exacerbations of COPD. The rate of total exacerbations was $34 \%$ lower in the roflumilast $500 \mu \mathrm{g}$ group than in the placebo group ( $\mathrm{p}=0.0029$ test for trend) [23].

\section{Severe-to-very severe COPD trial}

The Effect of Roflumilast on Exacerbation Rate in Patients With Chronic Obstructive Pulmonary Disease (OPUS) trial was a 52week, multicentre, double-blind comparison of roflumilast $500 \mu \mathrm{g}$ once daily versus placebo added to ongoing optimised conventional therapy in 1,513 patients with COPD [24].

The patients in the OPUS trial had more advanced COPD than those in the 24-week trial of roflumilast. The mean postbronchodilator FEV1 for patients in this trial was $41 \%$ pred versus $54 \%$ in the 24 -week study, and the respective FEV1/FVC values were 41 and $50 \%$. In addition, $\sim 63 \%$ of patients in this trial were taking ICS versus $21 \%$ in the 24 -week trial $[23,24]$.

Results from this trial, like those from the 24-week study, indicated significant superiority of roflumilast over placebo.

Patients treated with placebo had a decline in FEV1 characteristic of COPD versus improvement with roflumilast (fig. 7). This difference was statistically significant by 4 weeks and was maintained for the duration of the trial. At 52 weeks, there was a 45-mL difference in FEV1 for roflumilast versus placebo $(p<0.001)$ [24]. Overall, roflumilast treatment resulted in no significant reduction in the frequency of exacerbations versus placebo (fig. 8; $\mathrm{p}=0.390$ ). However, the patients enrolled in this trial had an exacerbation rate of $<1$ per yr and this may have 


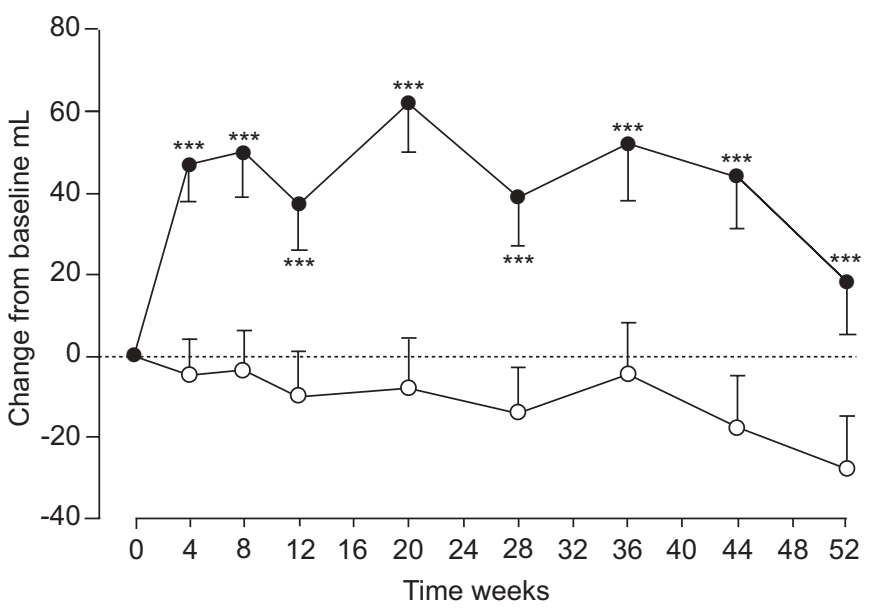

FIGURE 7. Change from baseline to 52 weeks in patients who had roflumilast $500 \mu \mathrm{g}$ or placebo added to ongoing treatment for chronic obstructive pulmonary disease (COPD). Results are from the Effect of Roflumilast on Exacerbation Rate in Patients With Chronic Obstructive Pulmonary Disease (OPUS) trial, a 52-week, multicentre, double-blind comparison of roflumilast $500 \mu \mathrm{g}$ once daily versus placebo added to ongoing optimised conventional therapy in 1,513 patients with COPD. Data are presented as least significant mean and SEM. - roflumilast; $\bigcirc$ : placebo. ${ }^{* \star *}: p=0.001$ versus placebo. Reproduced and modified from [24] with permission from the publisher.

been too low to permit demonstration of roflumilast efficacy for this end-point. This suggestion is supported by the fact that roflumilast treatment significantly reduced the annual exacerbation rate by $36 \%$ from 1.59 to 1.01 in Global Initiative for Chronic Obstructive Lung Disease (GOLD) stage IV patients who were most prone to exacerbations (fig. 8; $p=0.012$ ) [24].

\section{Safety}

Comparison of safety data for roflumilast with those for cilomilast indicated that gastrointestinal adverse events (diarrhoea, nausea) occurred more often in patients treated with roflumilast than with placebo, but that the rates of these side effects were lower than those reported for cilomilast. Unlike cilomilast, vomiting was not observed in patients treated with roflumilast and the frequency of gastrointestinal adverse events declined with continued treatment [20, 23]. The apparent difference between the tolerabilities of roflumilast and cilomilast may be due to the fact that roflumilast does not specifically target PDE4D, which is highly expressed in portions of the brain involved in emesis and appears to have inhibitory effects on this response. Cilomilast is highly selective for PDE4D and this may be the reason for its high risk for gastrointestinal adverse events [19, 21, 22, 25]. These results support the view that development of PDE4 inhibitors that are highly selective for PDE4D is probably not the best approach for achieving both efficacy and good tolerability.

\section{CONCLUSION}

The results summarised in the present brief article indicate that PDE4 inhibitors have a wide spectrum of anti-inflammatory effects in COPD, with beneficial actions on neutrophils, eosinophils, monocyte/macrophages, mast cells, airway smooth muscle cells, CD8+ cells and pro-inflammatory cytokines. Roflumilast and cilomilast are the PDE4 inhibitors
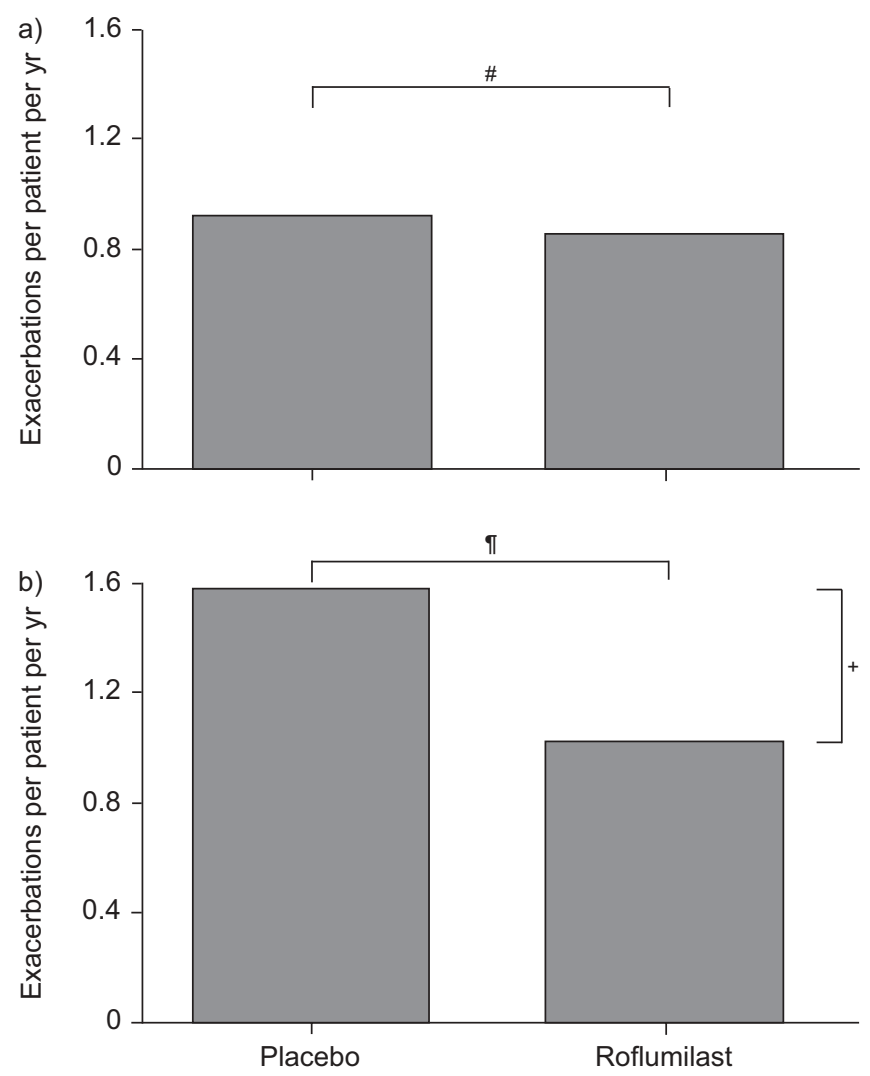

FIGURE 8. Efficacy of roflumilast $500 \mu \mathrm{g}$ versus placebo in decreasing chronic obstructive pulmonary disease (COPD) exacerbations over 52 weeks in a) the overall study population and b) patients with very severe COPD. Results are from the Effect of Roflumilast on Exacerbation Rate in Patients With Chronic Obstructive Pulmonary Disease (OPUS) trial, a 52-week, multicentre, double-blind comparison of roflumilast $500 \mu \mathrm{g}$ once daily versus placebo added to ongoing optimised

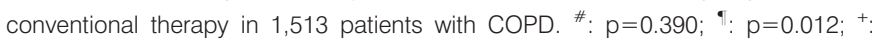
$\Delta 36 \%$. Data from [25].

that have been used most extensively in patients with COPD. Roflumilast has been shown to significantly improve FEV1 in patients with either moderate-to-severe or severe-to-very severe COPD and to significantly decrease exacerbations, particularly in patients with severe COPD. Roflumilast treatment also produced significant improvements in health-related quality of life, as reflected by SGRQ scores. Roflumilast is well tolerated by patients with COPD with a low rate of gastrointestinal adverse events that decreases with continued treatment. Clinical trials with cilomilast have produced much more varied results. Significant improvements in FEV1 and reductions in exacerbation rates versus placebo were observed in only two of four 24-week trials with this PDE4 inhibitor. Cilomilast also has a high risk for gastrointestinal toxicity that does not appear to dissipate over 24 weeks of treatment.

While further research is needed to define the place in chronic obstructive pulmonary disease therapy for phosphodiesterase 4 inhibitors, they are attractive agents for several reasons. First, their anti-inflammatory profile appears to differ from that of corticosteroids; roflumilast was specifically designed to target the inflammation characteristic of chronic obstructive pulmonary disease. Secondly, these new orally administered agents 
reach the systemic circulation and have the potential to blunt the inflammatory processes involved in many of the comorbidities of chronic obstructive pulmonary disease, further improving outcomes for these patients. One drug in this class, roflumilast, will be the first oral, steroid-free, once-daily antiinflammatory agent for the treatment of chronic obstructive pulmonary disease.

\section{REFERENCES}

1 Rennard SI. Treatment of stable chronic obstructive pulmonary disease. Lancet 2004; 364: 791-802.

2 Barnes PJ, Hansel TT. Prospects for new drugs for chronic obstructive pulmonary disease. Lancet 2004; 364: 985-996.

3 Rennard SI. Chronic obstructive pulmonary disease: linking outcomes and pathobiology of disease modification. Proc Am Thorac Soc 2006; 3: 276-280.

4 Andreas S, Anker SD, Scanlon PD, Somers VK. Neurohumoral activation as a link to systemic manifestations of chronic lung disease. Chest 2005; 128: 3618-3624.

5 de Vries F, van Staa TP, Bracke MS, Cooper C, Leufkens HG, Lammers JW. Severity of obstructive airway disease and risk of osteoporotic fracture. Eur Respir J 2005; 25: 879-884.

6 Calverley PM, Anderson JA, Celli B, et al. Salmeterol and fluticasone propionate and survival in chronic obstructive pulmonary disease. N Engl J Med 2007; 356: 775-789.

7 Barnes PJ. Medical progress: chronic obstructive pulmonary disease. N Engl J Med 2000; 343: 269-280.

8 Lugnier C. Cyclic nucleotide phosphodiesterase (PDE) superfamily: a new target for the development of specific therapeutic agents. Pharmacol Ther 2006; 109: 366-398.

9 Vignola AM. PDE4 inhibitors in COPD - a more selective approach to treatment. Respir Med 2004; 98: 495-503.

10 Odashima M, Otaka M, Jin M, et al. Rolipram, a specific type IV phosphodiesterase inhibitor, ameliorates aspirininduced gastric mucosal injury in rats. Dig Dis Sci 2005; 50: 1097-1102.

11 Tang HF, Chen JQ, Xie QM, et al. The role of PDE4 in pulmonary inflammation and goblet cell hyperplasia in allergic rats. Biochim Biophys Acta 2006; 1762: 525-532.

12 Buhl R, Farmer SG. Future directions in the pharmacologic therapy of chronic obstructive pulmonary disease. Proc Am Thorac Soc 2005; 2: 83-93.

13 Fan Chung K. Phosphodiesterase inhibitors in airways disease. Eur J Pharmacol 2006; 533: 110-117.
14 Hatzelmann A, Schudt C. Anti-inflammatory and immunomodulatory potential of the novel PDE4 inhibitor roflumilast in vitro. J Pharmacol Exp Ther 2001; 297: 267-279.

15 Mata M, Sarria B, Buenestado A, Cortijo J, Cerda M, Morcillo EJ. Phosphodiesterase 4 inhibition decreases MUC5AC expression induced by epidermal growth factor in human airway epithelial cells. Thorax 2005; 60: 144-152.

16 Jones NA, Boswell-Smith V, Lever R, Page CP. The effect of selective phosphodiesterase isoenzyme inhibition on neutrophil function in vitro. Pulm Pharmacol Ther 2005; 18: 93-101.

17 Martorana PA, Beume R, Lucattelli M, Wollin L, Lungarella G. Roflumilast fully prevents emphysema in mice chronically exposed to cigarette smoke. Am J Respir Crit Care Med 2005; 172: 848-853.

18 Grootendorst DC, Gauw SA, Verhoosel RM, et al. The PDE4 inhibitor roflumilast reduces sputum neutrophil and eosinophil numbers in patients with COPD. Thorax 2007; [Epub ahead of print PMID: 17573446].

19 Giembycz MA. An update and appraisal of the cilomilast phase III clinical development programme for chronic obstructive pulmonary disease. Br J Clin Pharmacol 2006; 62: 138-152.

20 Airflo (cilomilast) NDA presentation. Pulmonary - Allergy Drugs Advisory Committee Meeting. September 5, 2003. www.fda.gov/OHRMS/DOCKETS/AC/03/slides/3976S1_ 01_Glaxo-Ariflo.ppt. Date last updated: September 5, 2003. Date last accessed: June 20, 2007.

21 Giembycz MA. 4D or not 4D - the emetogenic basis of PDE4 inhibitors uncovered? Trends Pharmacol Sci 2002; 23: 548 .

22 Robichaud A, Stamatiou PB, Jin SL, et al. Deletion of phosphodiesterase $4 \mathrm{D}$ in mice shortens $\beta_{2}$-adrenoceptormediated anesthesia, a behavioral correlate of emesis. J Clin Invest 2002; 110: 1045-1052.

23 Rabe KF, Bateman ED, O'Donnell D, Witte S, Bredenbroker D, Bethke TD. Roflumilast - an oral antiinflammatory treatment for chronic obstructive pulmonary disease: a randomised controlled trial. Lancet 2005; 366: 563-571.

24 Calverley PM, Sanchez-Toril F, McIvor RA, Teichmann P, Bredenbroeker D, Fabbri LM. Effect of 1 year treatment with roflumilast in severe chronic obstructive pulmonary disease. Am J Respir Crit Care Med 2007; 176: 154-161.

25 Lipworth BJ. Phosphodiesterase-4 inhibitors for asthma and chronic obstructive pulmonary disease. Lancet 2005; 365: 167-175. 